\title{
FLOW BOILING IN A 1.1 MM TUBE WITH R134A - EXPERIMENTAL RESULTS AND COMPARISON WITH MODEL
}

\author{
D. Shiferaw, T.G. Karayiannis, D.B.R. Kenning \\ School of Engineering and Design, Brunel University, West London, \\ Uxbridge, Middlesex, UB8 3PH, UK, email: tassos.karayiannis@brunel.ac.uk
}

\begin{abstract}
A detailed comparison of the three-zone evaporation model, proposed by Thome et al. (2004), with experimental heat transfer results of two stainless steel tubes of internal diameter $4.26 \mathrm{~mm}$ and $2.01 \mathrm{~mm}$ using R134a fluid was presented by Shiferaw et al. (2006). In the current paper the comparison is extended to flow boiling in a $1.1 \mathrm{~mm}$ tube using $\mathrm{R} 134 \mathrm{a}$ as the working fluid. Other parameters were varied in the range: mass flux $100-600 \mathrm{~kg} / \mathrm{m}^{2} . \mathrm{s}$; heat flux $16-150 \mathrm{~kW} / \mathrm{m}^{2}$ and pressure 6-12 bar.

The experimental results demonstrate that the heat transfer coefficient increases with heat flux and system pressure, but does not change with vapour quality when the quality is less than about $50 \%$ for low heat and mass flux values. The effect of mass flux is observed to be insignificant. For vapour quality values greater than $50 \%$ and at high heat flux values, the heat transfer coefficient does not depend on heat flux and decreases with vapour quality. This could be caused by partial dryout. The three-zone evaporation model predicts the experimental results fairly well, especially at relatively low pressure. However, the partial dryout region is highly over-predicted by the model. The sensitivity of the performance of the model to the three optimized parameters (confined bubble frequency, initial film thickness and end film thickness) and some preliminary investigation relating the critical film thickness for dryout to measured tube roughness are also discussed.
\end{abstract}

\section{INTRODUCTION}

In recent years there has been increased research activity in flow boiling in very small diameter tubes and it is now highly desirable to develop mechanistic models for flow boiling in small to micro-channels that are well validated by experiments. Conventional ways of modelling boiling heat transfer coefficients in large channels are mainly based on empirical correlations and do not consider the effect of flow regime on heat transfer. Flow boiling heat transfer models have been proposed and are published in past papers, based on nucleate boiling, forced convective boiling, film flow boiling and annular two phase flow boiling. Experimental results for small diameter tubes also demonstrated heat transfer coefficients that were more or less independent of vapour quality and mass flux, but strongly dependent on heat flux and saturation pressure, (Lazarek and Black (1982), Wambsganss et al. (1993), Tran et al. (1996), Bao et al. (2000), Palm (2003), Huo et al. (2007)). Conventionally, this is interpreted as evidence that nucleate boiling is the dominant heat transfer mechanism. However, using macroscale boiling heat transfer correlations and models based on the above premise did not predict well the heat transfer coefficient in small diameters, $\mathrm{Qu}$ and Mudawar (2003), Owhaib and Palm (2003) and Huo et al. (2007).

Currently emerging flow regime based models provide a more realistic description of the various transport process from which important hydrodynamic and thermal parameters such as heat transfer and pressure drop can be derived. Recently, Thome et al. (2004) proposed a model based on convective heat 
transfer in three zones within the confined bubble regime, without any contribution from nucleate boiling.

Most models, including the three-zone model, do not at present take fluctuations in saturation temperature into account. Yan and Kenning (1998) showed that the pressure fluctuations were caused by the acceleration of liquid slugs by expanding confined bubbles, confirming a model of Kew and Cornwell (1996), and that the corresponding fluctuations in saturation temperature were of similar magnitude to the mean superheat causing evaporation, so they could not be neglected. Zhang et al. $(2004,2005)$ showed that the fluctuations in pressure, saturation temperature and wall temperature became more extreme for water boiling in microchannels with cross-sectional dimensions below $0.17 \mathrm{~mm}$, so that they might influence mechanical integrity as well as thermal performance.

In channels of circular cross-section, in which events in the boiling region cannot be observed directly, decreases in time averaged heat transfer coefficient with increasing quality, often accompanied by fluctuating wall temperatures, have been attributed to transient dryout, particularly at low mass flux, and relatively high heat flux, Lin et al. (2001), Yan and Lin (1998), Huo et al. (2007). Wen et al. (2002) observed at very low mass fluxes the downstream propagation of transient high wall temperatures indicative of dryout, even at low heat fluxes. Microchannel heat transfer correlations generally do not make allowance for partial dry out. However, the three-zone model includes a mechanism of periodic dryout.

Shiferaw et al. (2006) compared the experimental results, obtained with two stainless steel tubes of internal diameter 4.26 $\mathrm{mm}$ and $2.01 \mathrm{~mm}$ using R134a at 8 bar and 12 bar system pressure, with the three- zone evaporation model for confined bubble flow proposed by Thome et al. (2004). They observed that the model predicted fairly well the experimental data that could have been previously interpreted as nucleate boiling due to their dependence on heat flux and independence of quality. However, it did not predict correctly the trends for changing pressure and diameter. Shiferaw et al. also pointed out other features of the model that may require improvement. In the current paper the comparison is extended to heat transfer results for a $1.1 \mathrm{~mm}$ tube, including high quality regions where partial dry out is deduced to occur.

The main features of the model, described briefly in Section 2, include three empirically determined constants, namely frequency of formation of confined bubbles, thickness of the thin film formed round a confined bubble and a critical value of the film thickness for dryout to occur, which is tentatively associated with the wall roughness.

\section{NOMENCLATURE}

\begin{tabular}{|ll|}
\hline$B o$ & Bond number, $B o=\frac{\rho_{l} d}{\sigma} U_{p}{ }^{2}$ \\
$C_{\delta 0}$ & correcting factor on the initial film thickness \\
$\mathrm{d}$ & internal diameter, $\mathrm{m}$ \\
$f$ & pair frequency $(\mathrm{Hz}), f=\frac{1}{\tau}$ \\
$G$ & mass flux, $\mathrm{kg} / \mathrm{m}^{2} s$ \\
$h_{l v}$ & latent heat of vaporization $(\mathrm{J} / \mathrm{kg})$ \\
$\mathrm{L}$ & length, m \\
$N u$ & Nusselt number, \\
\hline
\end{tabular}

\begin{tabular}{|ll|}
\hline $\mathrm{P}$ & pressure, bar \\
$q$ & heat flux, $W / \mathrm{m}^{2}$ \\
$t$ & time (sec) \\
$U$ & bubble velocity, $\mathrm{m} / \mathrm{sec}$ \\
$\mathrm{x}$ & vapour quality \\
$z$ & axial distance \\
Greek & \\
$\delta$ & liquid film thickness, (m) \\
$\sigma$ & surface tension, $\mathrm{N} / \mathrm{m}$ \\
$\lambda$ & thermal conductivity $(W / m \cdot K)$ \\
$\alpha$ & heat transfer coefficient, $W /\left(\mathrm{m}^{2} \mathrm{~K}\right)$ \\
$v$ & kinematic viscosity, $\mathrm{m}^{2} / \mathrm{s}$ \\
$\tau$ & pair period (s) \\
$\rho$ & density, $\mathrm{kg} / \mathrm{m}^{3}$ \\
Subscripts & \\
crit & critical \\
$d r y$ & dryout zone \\
dry film & dryout of liquid film \\
end & end of the liquid film \\
film & liquid film between bubble and wall \\
$l$ & Liquid \\
min & Minimum \\
opt & Optimum \\
$p$ & Pair \\
ref & Reference \\
sat & Saturation \\
tot & Total \\
$t p$ & two phase \\
$v$ & Vapour \\
0 & Initial \\
\hline & \\
\hline
\end{tabular}

\section{REVIEW OF THE MODEL}

A brief review of the three-zone model developed by Thome and co-workers was presented in Shiferaw et al. (2006) and is now included here for the sake of completeness. The full details are given in Thome et al. (2004) and Dupont et al. (2004). The proposed model predicts the local dynamic and the local time-averaged heat transfer coefficient at fixed locations along the channel based on the evaporation of elongated bubbles.

Figure 1 illustrates the three-zone model. The model assumes the passage of a liquid slug followed by a confined elongated bubble trapping a thin liquid film against the inner wall, which means the existence of a pair consisting of the liquid slug and the elongated bubble. However, if the liquid film dries out by evaporation before the arrival of the next liquid slug, a vapour slug follows (triplet). The fact that the model considers a dryout zone and exploits the transient evaporation of the film is one of the novelties of the model. Nucleate boiling is not included in the model. 


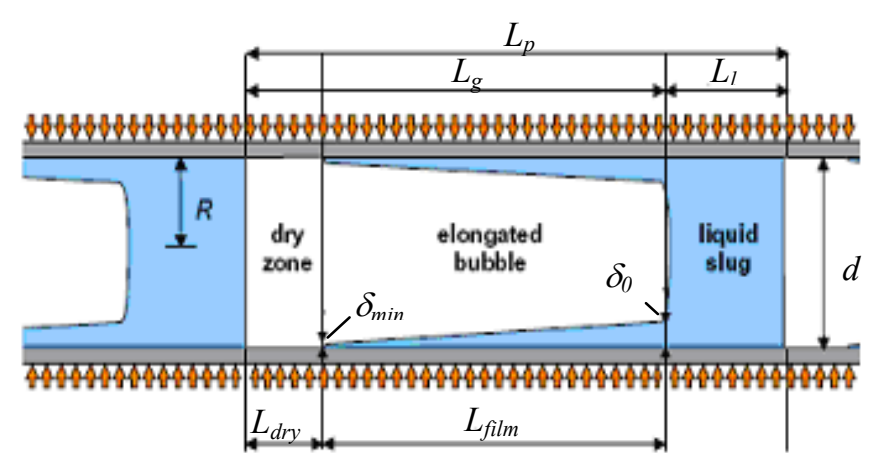

Figure 1: Diagram illustrating the three zones: a liquid slug, an elongated bubble and a vapour slug, Thome et al. (2004).

The time-averaged local heat transfer coefficient is determined by,

$$
\alpha_{t p}(z)=\frac{t_{l}}{\tau} \alpha_{l}(z)+\frac{t_{f i l m}}{\tau} \alpha_{f i l m}(z)+\frac{t_{d r y}}{\tau} \alpha_{v}(z)
$$

The time periods used in the model are as follows: $t_{l}$ corresponds to the time it takes for the liquid slug to pass a fixed location $\mathrm{z}$ through the cross section, $t_{l}=\tau /\left(1+\left(\rho_{l} / \rho_{v}\right)(x / 1-x)\right) ; t_{\text {film }}$ is the residence time of the film; $t_{d r y}$ represents the duration of the local wall dryout; $t_{v}$ corresponds to the presence of vapour (dryout and film zone) passing location $\mathrm{z}, \quad t_{v}=\tau /\left(1+\left(\rho_{v} / \rho_{l}\right)(1-x) / x\right)$. The maximum duration, $t_{d r y}$ film , of the existence of the film at position $\mathrm{z}$ till dryout occurs at the minimum feasible film thickness $\left(\delta_{\text {min }}\right)$ is $t_{d r y \text { film }}(z)=\left(\rho_{l} h_{l v} / q\right)\left(\delta_{0}(z)-\delta_{\text {min }}\right)$. If $t_{d r y}$ film $<t_{v}$, local dryout occurs, i.e. the liquid film thickness reaches the minimum feasible film thickness, $\delta_{\text {end }}(z)=\delta_{\text {min }}$, and $t_{f i l m}=$ $t_{d r y}$ film, Thome et al. (2004). This implies that $t_{d r y}=t_{v}-t_{\text {film }}$. On the other hand if $t_{d r y f i m}>t_{v}$, then no dryout occurs since the next liquid slug arrives before dryout of the film occurs and, $\delta_{\text {end }}(z)$ $=\delta\left(z, t_{v}\right)$, In this case, $t_{\text {film }}=t_{v}$.

$\alpha_{l}(z)$ and $\alpha_{v}(z)$ are calculated from their local Nusselt numbers using the respective equivalent lengths $\mathrm{L}_{1}$ and $\mathrm{L}_{\mathrm{dry}}$, see Figure $1 . \mathrm{L}_{1}$ and $\mathrm{L}_{\text {dry }}$ are the length of the liquid slug and dry wall zone respectively. The London and Shah correlation for laminar developing flow and the Gnielinski (1976) correlation for transition and turbulent developing flow was recommended by Thome et al. (2004). The Churchill and Usagi (1972) asymptotic method was used to obtain a continuous expression of the mean heat transfer coefficient as a function of Reynolds number.

The mean heat transfer coefficient through the evaporating thin liquid film surrounding the elongated bubble, $\alpha_{\text {film }}(z)$, was obtained as follows assuming one-dimensional heat conduction in a stagnant thin liquid film:

$$
\begin{gathered}
\alpha_{f i l m}(z)=\frac{\lambda_{1}}{\delta_{0}-\delta_{\text {end }}} \ln \left(\frac{\delta_{0}}{\delta_{\text {end }}}\right) \\
\delta(z, t)=\delta_{0}(z)-\frac{q}{\rho_{l} h_{l v}} t \\
\frac{\delta_{0}}{d}=C_{\delta_{0}}\left(3 \sqrt{\frac{v_{l}}{U_{p} d}}\right)^{0.84}\left[\left(0.07 B o^{0.41}\right)^{-8}+0.1^{-8}\right]^{-1 / 8} \\
\text { where } \quad U_{p}=G_{t o t}\left[\frac{x}{\rho_{v}}+\frac{1-x}{\rho_{l}}\right]
\end{gathered}
$$

In the model, three parameters were not defined analytically, namely the minimum thickness of the liquid film at dryout $\left(\delta_{\min }\right)$, the pair frequency $(f)$, which is the frequency of the bubble generation and the correction factor, $C_{\delta 0}$ for the initial film thickness. They recommended values of these parameters to be found by optimising the prediction of the model against an experimental database for the heat transfer coefficient. The initial thickness of the liquid film was found by using the Moriyama and Inoue (1996) film thickness prediction and applied an empirical correction factor, $C_{\delta 0}$ as shown in equation (4). In Thome et al. (2004), it was presented that the film thickness was governed by the evaporation of the liquid film. However, in Dupont et al. (2004), where they compared the model predictions with a database (1591 test data for R11, R12，R113，R123，R134a，R141b and $\mathrm{CO}_{2}$ ), they used a constant average film thickness. After optimising empirically each parameter with the whole range of the database, they recommended general values of the parameters as:

$$
\begin{gathered}
\delta_{\min }=0.3 \mu \mathrm{m} \\
f_{\text {opt }}=\left(\frac{q}{q_{\text {ref }}}\right)^{1.74} \mathrm{~Hz}
\end{gathered}
$$

The reference heat flux $\left(q_{\text {ref }}\right)$ was given as a function of the reduced pressure based on the method employed by Cooper (1984) for the pool boiling correlation.

$$
q_{\text {ref }}=3328\left(\frac{P_{\text {sat }}}{P_{\text {crit }}}\right)^{-0.5}
$$

The constant values of $3328 \mathrm{~W} / \mathrm{m}^{2}$ as well as the values of the exponents of equation (7) and (8), i.e. 1.74 and -0.5 , respectively were obtained from the complete experimental database (which included R134a). The constant in equation (4) was again obtained using the database as:

$$
C_{\delta 0}=0.29
$$

In the current paper, the local and average heat transfer coefficients that were used to compare with the results of the current experiments were calculated using the above recommended general values, equations (6) - (9). It is desirable however to obtain independent estimates of the three parameters from detailed observations. 


\section{EXPERIMENTAL RESULTS}

An experimental facility was constructed during the early part of this study to determine the heat transfer coefficient in small diameter tubes using R134a fluid. A detailed description and a schematic are available in Huo et al. (2006). The test section was a stainless steel cold drawn tube of internal diameter $1.1 \mathrm{~mm}$, heated length $150 \mathrm{~mm}$, wall thickness 0.247 $\mathrm{mm}$ and roughness $1.28 \mu \mathrm{m}$. Direct electric heating was applied to the test section; fifteen K-type thermocouples were soldered to the outside of the tube at equal distances to provide the wall temperatures. The first and last thermocouple readings were not used in the analysis so as to avoid conduction errors. T-type thermocouples and pressure transducers were used to measure inlet and outlet temperatures and pressures. An energy balance based on the electrical heat supplied minus losses and the enthalpy change enabled the local quality to be calculated at each thermocouple position. The total enthalpy change across the test section was calculated based on the flow rate of the refrigerant and the pressure and temperature change measured by the differential pressure transducer and thermocouple, respectively, at two ends of the test section. All the instruments used were carefully calibrated. The uncertainty in temperature measurement was $\pm 0.2 \mathrm{~K}$, flow rate measurements $\pm 0.4 \%$, and pressure measurements $\pm 0.15 \%$. The average error in the heat transfer coefficient was $\pm 6 \%$. A validation was performed using single phase pressure drop and heat transfer tests before running the boiling experiment. The single phase friction factor results agreed well with the Blasius correlation, i.e. within the uncertainty of the experiment. Also, the single phase Nusselt number $(\mathrm{Nu})$ results agreed very well with the Dittus-Boetler and Petukhov correlations, again within the uncertainty limit. A series of flow boiling tests were performed at different mass flux and heat flux. In the heat transfer experiments, the fluid inlet temperature was kept slightly below saturation and the heat flux was increased in steps until the exit quality reached about $90 \%$ for a fixed mass flux and system pressure. A Pyrex glass tube for flow pattern observation was located immediately downstream of the heat transfer test section. A digital highspeed camera (Phantom V4 B/W, 250 x 512 pixels resolution, 2000 pictures/sec) was used to observe the flow patterns. The results of the flow visualization part of this study are presented in detail in Chen et al. (2006). The local flow boiling heat transfer coefficients for R134a were obtained for the range: pressure 6 to $12 \mathrm{bar}$, heat flux $16-170 \mathrm{~kW} / \mathrm{m}^{2}$, mass flux 100 $600 \mathrm{~kg} / \mathrm{m}^{2} \mathrm{~s}$, vapour quality $0-0.9$.

The experimental local heat transfer coefficient is plotted as a function of quality in Figure 2 and 3 for various heat fluxes. Figure 2 shows some of the typical results at a mass flux of $200 \mathrm{~kg} / \mathrm{m}^{2} \mathrm{~s}$ and 8 bar system pressure. As seen in the figure, when $\mathrm{x}<0.5$, the heat transfer coefficient depends on the heat flux and is almost independent of quality. At high values of heat flux, and vapour quality greater than $50 \%$, the heat transfer coefficient becomes independent of heat flux and decreases monotonically with quality. The decrease in heat transfer coefficient with increasing vapour quality may be due to the occurrence of partial dryout. At low values of heat flux, the heat transfer coefficient tends to depend on quality towards the exit of the test section.

Figure $3 \mathrm{a}$ and $\mathrm{b}$ depict similar curves to Figure 2, but for a system pressure of 6 bar and mass flux of 200 and $400 \mathrm{~kg} / \mathrm{m}^{2} \mathrm{~s}$ respectively. Again at low heat flux values, when $\mathrm{x}<0.5$ for $\mathrm{G}$
$=200 \mathrm{~kg} / \mathrm{m}^{2} \mathrm{~s}$ and $\mathrm{x}<0.3$ for $\mathrm{G}=400 \mathrm{~kg} / \mathrm{m}^{2} \mathrm{~s}$, the experimental heat transfer coefficient is nearly independent of quality and dependent on heat flux. In the same range of quality, as the heat flux increases to the highest value of $107 \mathrm{~kW} / \mathrm{m}^{2}$, the heat transfer coefficient begins to decrease with heat flux. When quality is greater than the above mentioned range, the heat transfer coefficient decreases with quality and becomes independent of heat flux. It can also be observed from figures 3(a) and (b) that the quality beyond which the heat transfer coefficient begins to decrease is lower at higher mass flux.

The heat transfer coefficient is depicted as a function of system pressure in Figure 4 for a mass flux of $300 \mathrm{~kg} / \mathrm{m}^{2} \mathrm{~s}$ and heat flux of $68 \mathrm{~kW} / \mathrm{m}^{2}$. The heat transfer coefficient increases with system pressure when $\mathrm{x}<0.6$. The increase in heat transfer coefficient with increasing saturation pressure could be due to the fact that bubble departure diameter decreases as the system pressure increases. The bubble departure frequency also increases with increase in pressure (Sharma et al. 1996). Threfore, bubble growth and departure from the tube wall is faster at high pressure values for the same heat flux. In nucleate boiling, the disturbance caused by bubbles growing and escaping from the wall contributes significantly to the heat transfer rate, Huo et al. (2007). Also, the effect of pressure on the specific heat of vaporization and liquid density may be an additional cause.

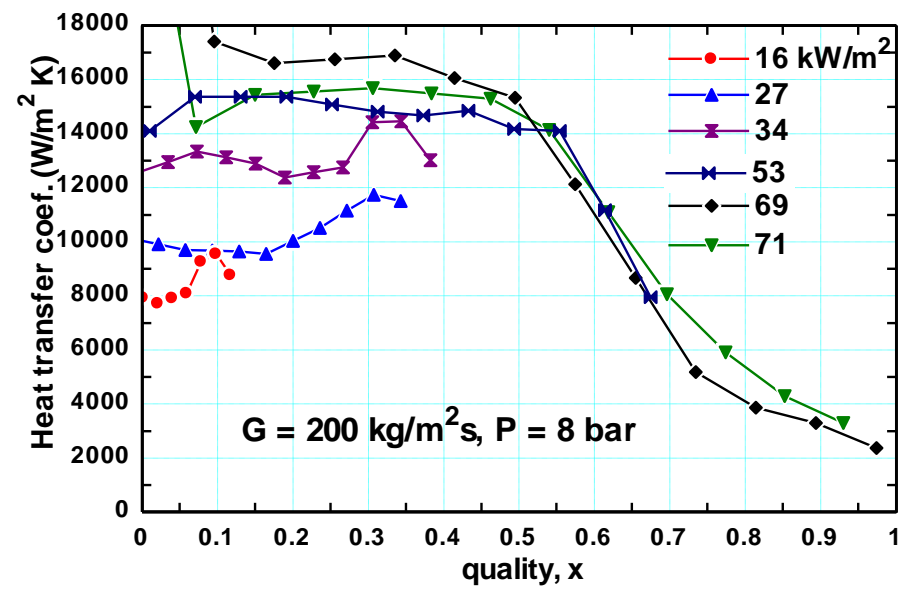

Figure 2: Local heat transfer coefficient as a function of vapour quality for various heat flux values; $G=200 \mathrm{~kg} / \mathrm{m}^{2} \mathrm{~s}, \mathrm{P}$ $=8$ bar.

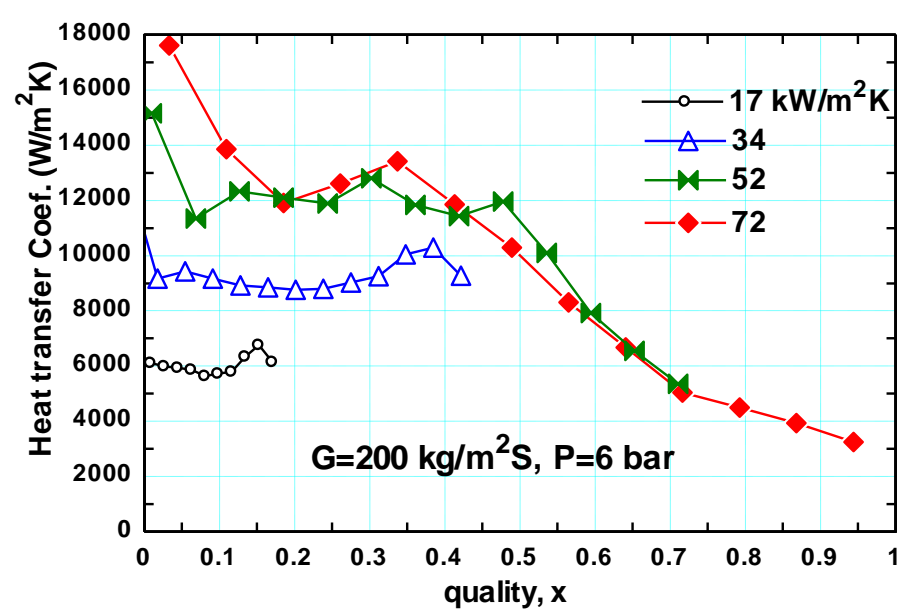


(a)

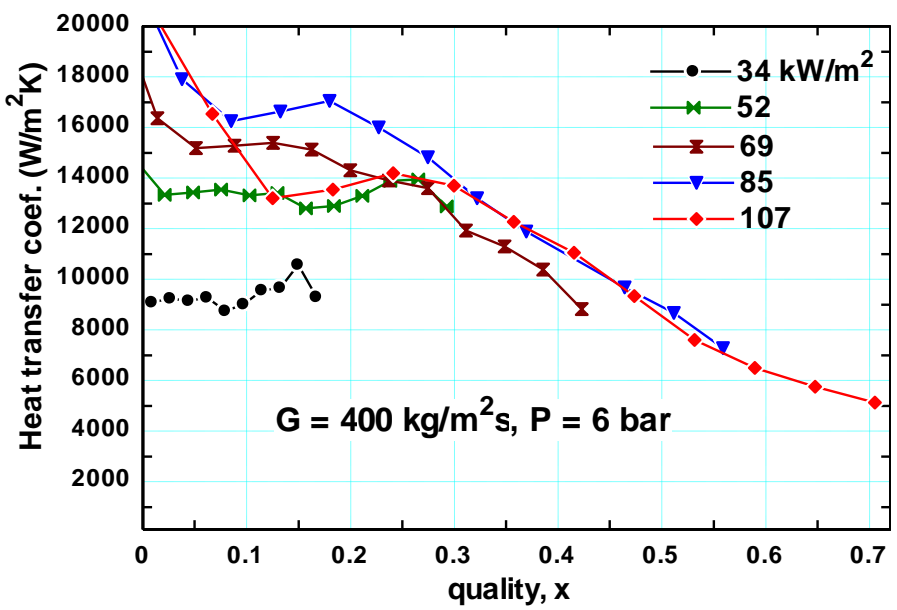

(b)

Figure 3: Local heat transfer coefficient as a function of vapour quality with various heat flux values; $P=6$ bar: (a) $G=$ $200 \mathrm{~kg} / \mathrm{m}^{2} \mathrm{~s}$ (b) $\mathrm{G}=400 \mathrm{~kg} / \mathrm{m}^{2} \mathrm{~s}$.

The dependence of the heat transfer coefficient on mass flux is depicted in Figure 5 for a heat flux of $69 \mathrm{~kW} / \mathrm{m}^{2}$ and 8 bar pressure. As seen in the figure, the heat transfer coefficient is almost independent of the mass flux.

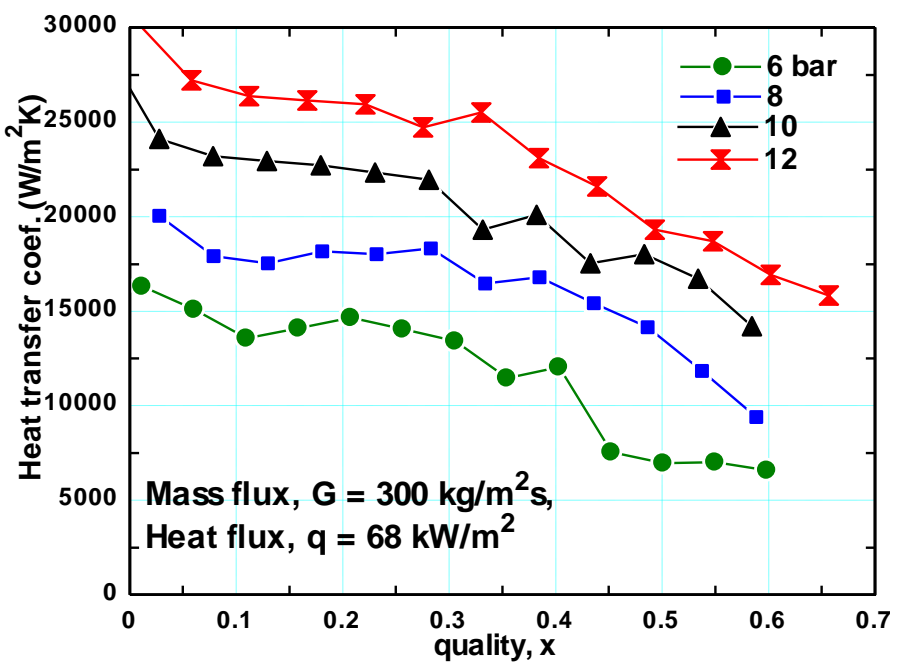

Figure 4: Local heat transfer coefficient as a function of vapour quality for various system pressures.

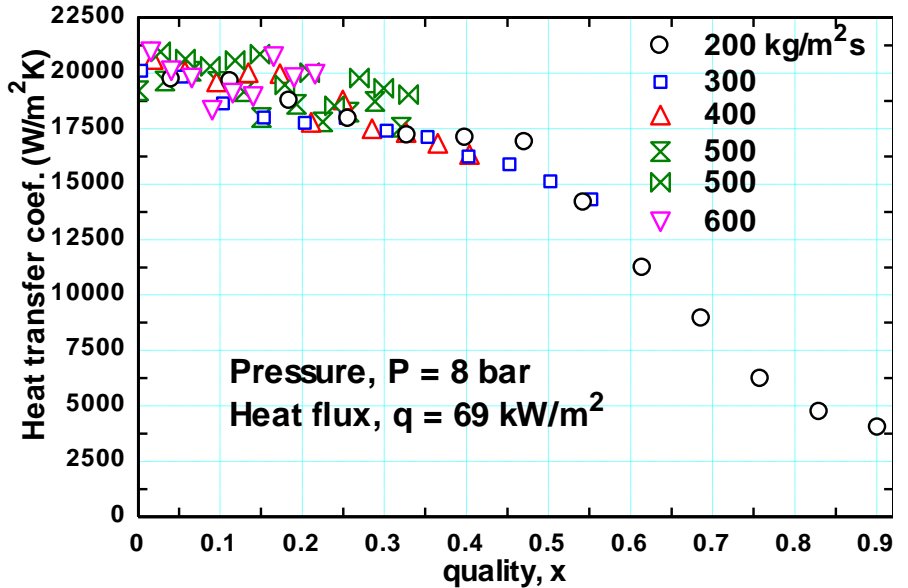

Figure 5: Local heat transfer coefficient as a function of vapour quality with various mass fluxes.

\section{COMPARISON WITH THE MODEL AND DISCUSSION}

In Figures 6-8, the experimental measurements of local heat transfer coefficient as a function of quality are compared with the predictions of the three-zone model of Thome et al. (2004), using the parameter values recommended by Dupont et al. (2004).

Figures $6 \mathrm{a}$ and $\mathrm{b}$ depict the effect of increasing heat flux at a pressure of 6 bar for mass fluxes of 200 and $400 \mathrm{~kg} / \mathrm{m}^{2} \mathrm{~s}$ respectively. At low heat fluxes, the experimental heat transfer coefficients increase with increasing heat flux; they are initially nearly independent of quality and then increase near the exit to the test section. At higher heat fluxes, the coefficients have maximum values at the first measuring point that increase with increasing heat flux. Initially, they decrease with increasing quality, then rise to a lower maximum. In this intermediate quality range, the dependence on heat flux is not straightforward: in Figure $6 \mathrm{~b}$, the heat transfer coefficients at $107 \mathrm{~kW} / \mathrm{m}^{2}$ fall below those at 69 and $85 \mathrm{~kW} / \mathrm{m}^{2}$. Beyond the

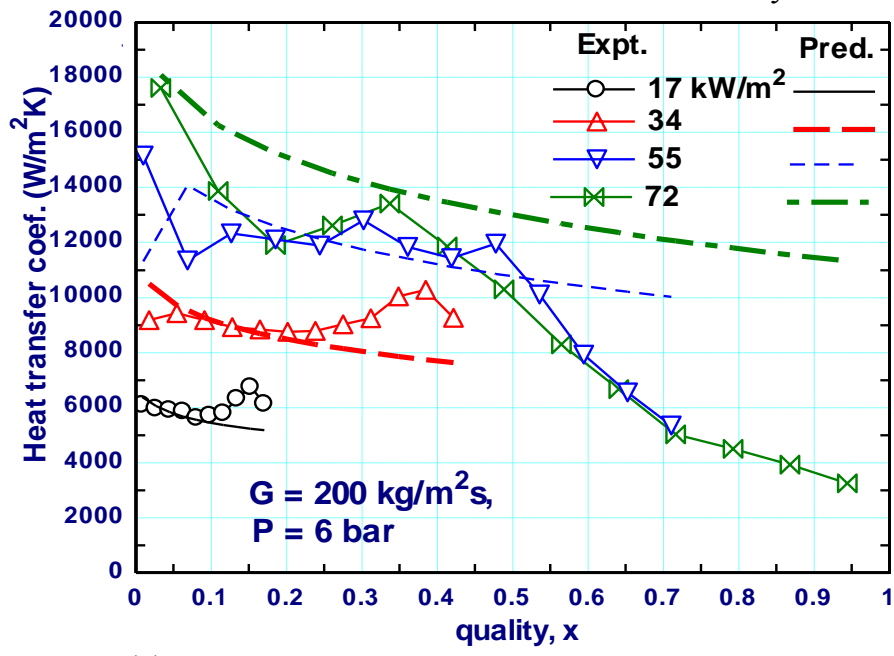

(a) 


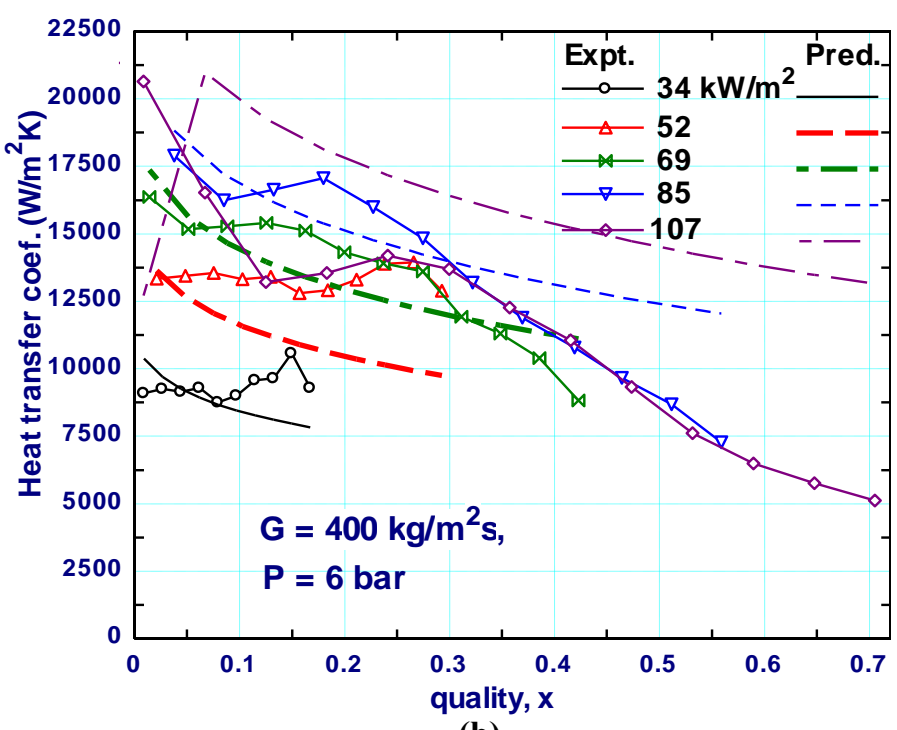

(b)

Figure 6: Comparison of the local heat transfer coefficient versus vapour quality with the model at various heat flux values and $P=6$ bar: (a) $G=200 \mathrm{~kg} / \mathrm{m}^{2} \mathrm{~s}$, (b) $\mathrm{G}=400 \mathrm{~kg} / \mathrm{m}^{2}$ s.

second maximum, the experimental points at all heat fluxes converge on a single line that decreases monotonically towards the test section exit. The predicted heat transfer coefficients exhibit simpler behaviour. They increase to a maximum around $\mathrm{x} \sim 0.05$ to 0.1 for both mass flux values, then decrease monotonically with increasing quality. The coefficients are always higher than the experimental values at the higher heat flux. The three-zone model predicts heat transfer coefficients of the right magnitude, without a contribution from nucleate boiling, but it does not predict their independence of heat flux at high qualities. It is evident that further development of the model is required but it is not clear whether this should be finetuning of the convective mechanism or the inclusion of nucleate boiling. The predicted decrease in heat transfer with increasing quality is primarily due to the mechanism of periodic dryout and is sensitive to the parameter values for the thin liquid film. It is tempting to attribute the experimental observations of decreasing heat transfer with increasing quality to the same mechanism of partial dryout but this does not explain the secondary maxima at intermediate qualities. There are other possible explanations, including a decreasing effect of nucleate boiling or a local critical heat flux that may be different in the confines of a small tube from the critical heat flux in pool boiling. In these experiments, it was not possible to make local observations to confirm or exclude the occurrence of nucleate boiling.

As seen in Figure 6a, for mass flux $200 \mathrm{~kg} / \mathrm{m}^{2} \mathrm{~s}$, at relatively low heat flux values, there is excellent agreement with the experimental values when $x<0.5$. In Figure $6 b$, the model under-predicts the uniform heat transfer coefficient region for heat flux values of 52 and $69 \mathrm{~kW} / \mathrm{m}^{2}$. For mass flux of both 200 and $400 \mathrm{~kg} / \mathrm{m}^{2} \mathrm{~s}$, at high heat flux values, the model over-predicts the experimental results, i.e. when $\mathrm{q}>72 \mathrm{~kW} / \mathrm{m}^{2}$ for mass flux of $200 \mathrm{~kg} / \mathrm{m}^{2} \mathrm{~s}$ and $\mathrm{q}>85 \mathrm{~kW} / \mathrm{m}^{2}$ for $400 \mathrm{~kg} / \mathrm{m}^{2} \mathrm{~s}$, the experimental heat transfer coefficient tends to decrease with heat flux and what may be partial dry out begins early.
However, the predicted heat transfer coefficient continues increasing with heat flux beyond the above limits.

In Figure $6 \mathrm{a}$ and $\mathrm{b}$, for heat flux $\mathrm{q}=55 \mathrm{~kW} / \mathrm{m}^{2}$ and 107 $\mathrm{kW} / \mathrm{m}^{2}$ respectively, the experimental heat transfer coefficient is under-estimated at very low vapour qualities, near $\mathrm{x}=0$. This may be attributable to the onset of nucleate boiling, i.e. exclusion of bubble formation in the unconfined bubbly flow region in the model. The model assumes all-liquid flow up to the inception of the confined bubbles at $\mathrm{x}=0$ and employs a laminar fully developed single-phase heat transfer correlation that gives heat transfer coefficients much lower than that of unconfined bubbly flow region.

Figure 7 compares the experimental and predicted effect of system pressure on the local heat transfer. The model predicted the lowest pressure $\mathrm{P}=6$ bar better than the rest. The trend with increasing system pressure is predicted correctly but the magnitude of the change is greatly under-predicted. This could be attributed to a limitation of the one-dimensional model, which does not solve the equation of motion for the liquid slug to allow for local variations in pressure. Alternatively, higher pressure gives higher vapour density that leads to lower vapour superficial velocity. As a result, pressure changes could cause a flow map shift, (i.e. a shift from the elongated bubble regime) which affects the model applicability. The model does not at present accommodate such variations.

It is noted above that there is no significant effect of mass flux on the experimental heat transfer coefficient. Figure 8 presents the same curve as Figure 5, now in comparison with the model prediction of a slight decrease in heat transfer coefficient with increasing mass flux. The coefficients predicted by the convective model are only about $20 \%$ below the experimental values, which is a warning against interpreting independence of mass flux as an indication of the dominance of nucleate boiling.

\section{PARAMETRIC SENSITIVITY OF THREE-ZONE MODEL}

As noted earlier, in the comparison with the model results, in all the above figures, the values used for the three parameters were those recommended by Dupont et al. (2004). Figure 9 shows the effect of varying each of these parameters, while keeping the others as given by their respective equations (6) to (9), on the predicted heat transfer coefficient for a sample case in which dryout appears to occur. Increasing the bubble generation frequency increases the predicted heat transfer coefficient by an amount that decreases with quality, Figure 9 a. At very low quality, (e.g. $\mathrm{x}<0.1$ ), a large increase in the frequency causes a sudden change in the character of the graph from a constant to a monotonic decrease. The sensitivity to the critical film thickness for dryout to occur, which is described as end film thickness in the model, is presented in Figure 9b. In the model, the dryout zone is directly linked to the value of the end film thickness. Increasing the end film thickness has an opposite effect on the heat transfer coefficient. In Figure 9c, the effect of changing the initial film thickness is depicted. Increasing the value increases the predicted heat transfer coefficient. Similar to the frequency curve, at higher initial film thickness, the curve changes its shape from monotonic increase to decreasing with quality at a low value of quality. 


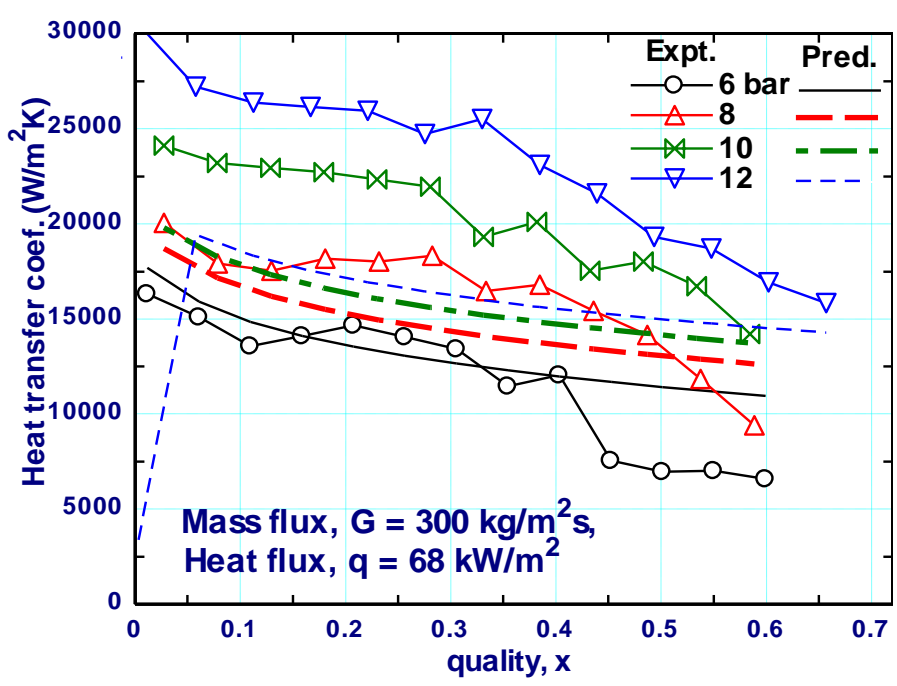

Figure 7: Effect of pressure on experimental and predicted local heat transfer coefficients at fixed mass flux and heat flux.

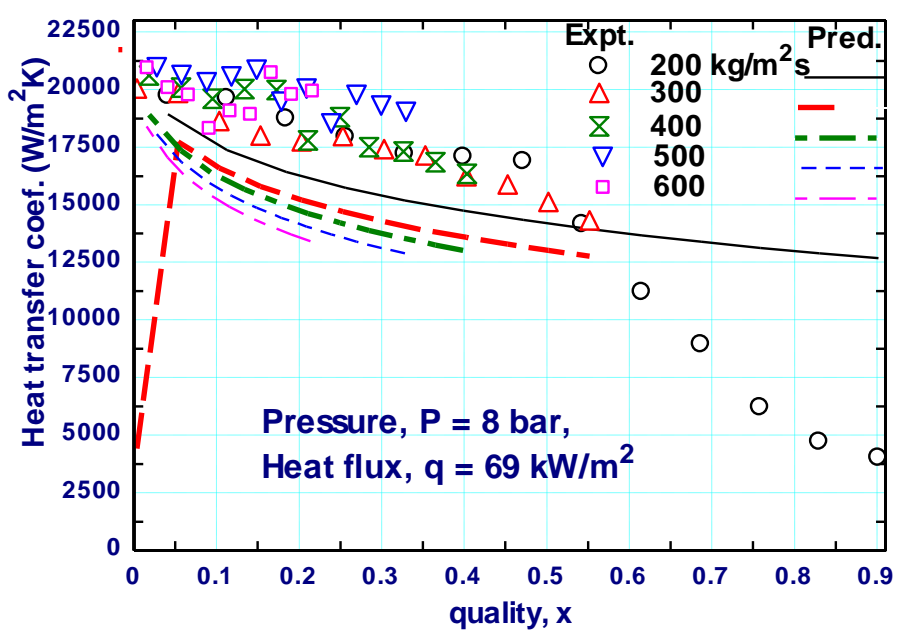

Figure 8: Effect of mass flux on experimental and predicted local heat transfer coefficients at fixed pressure and heat flux.

Figure $9 \mathrm{~d}$ presents the heat transfer predictions by the model when the end film thickness value $(1.3 \mu \mathrm{m})$ is made almost equal to the measured average roughness of the tube $(1.28 \mu \mathrm{m})$ and the other two parameters are modified, $C_{\delta 0}$ to 0.64 (2.2 times the standard value) and the frequency of bubble generation $(f)$ to 1.75 times that recommended by Dupont et al. (2004). This results in a greatly improved prediction of a case in which dryout appeared to occur early at low quality.

In general, the three-zone model can be made to predict the $1.1 \mathrm{~mm}$ tube heat transfer results at low quality fairly well. The model has a great potential for further improvement because it includes a mechanism of periodic dryout. However, the decreasing heat transfer coefficients at high qualities near the exit of the test section, attributed to partial dryout, are not predicted well by the model. Moreover, the fact that the three parameters in the model were optimised based on a large experimental database means that the model is not completely general and any genuine deviation in the prediction results could be compensated by the selection of these values. Therefore, further study leading to the independent evaluation of these parameters is necessary to make the model selfsufficient. Other features of the model that may require modification were suggested in Shiferaw et al. (2006).

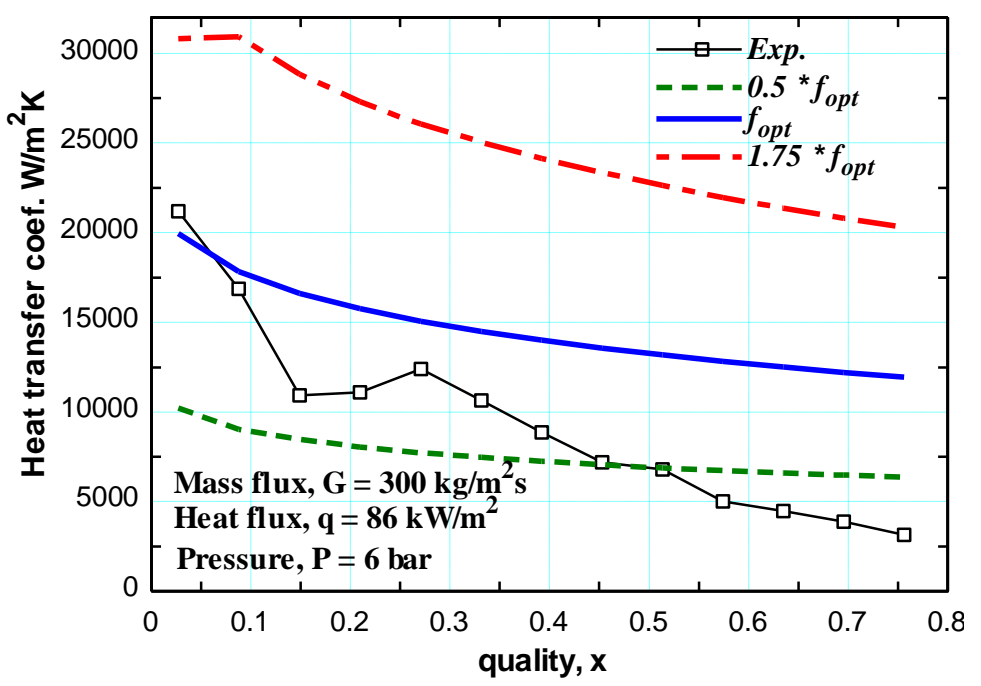

(a)

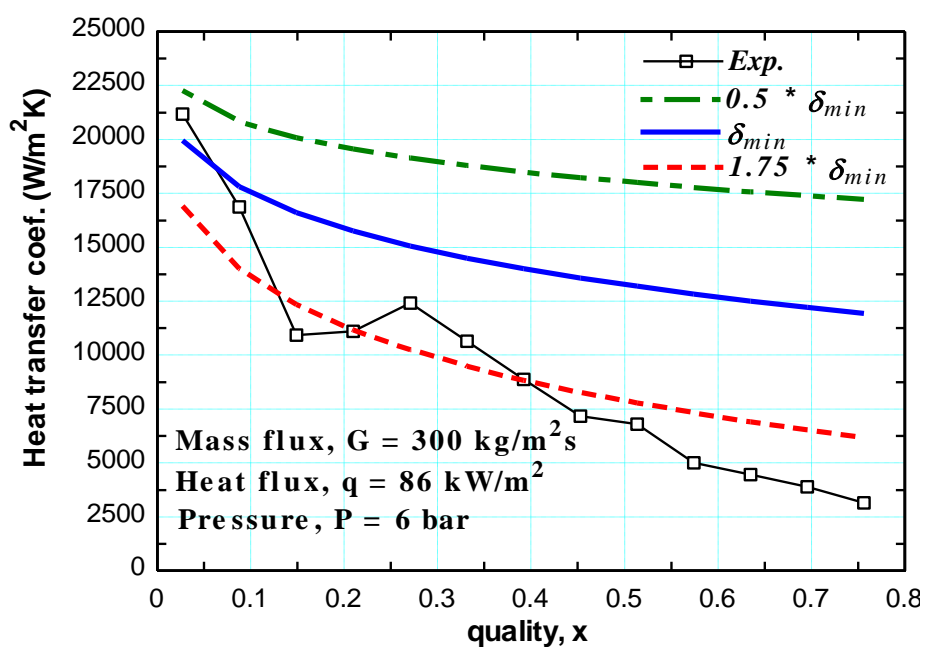

(b) 


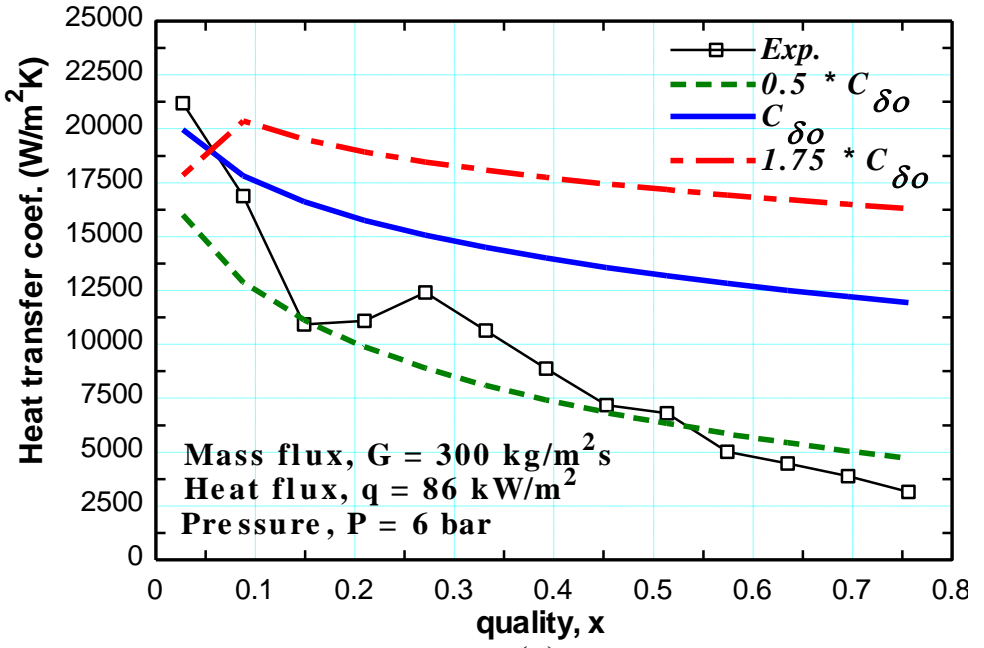

(c)

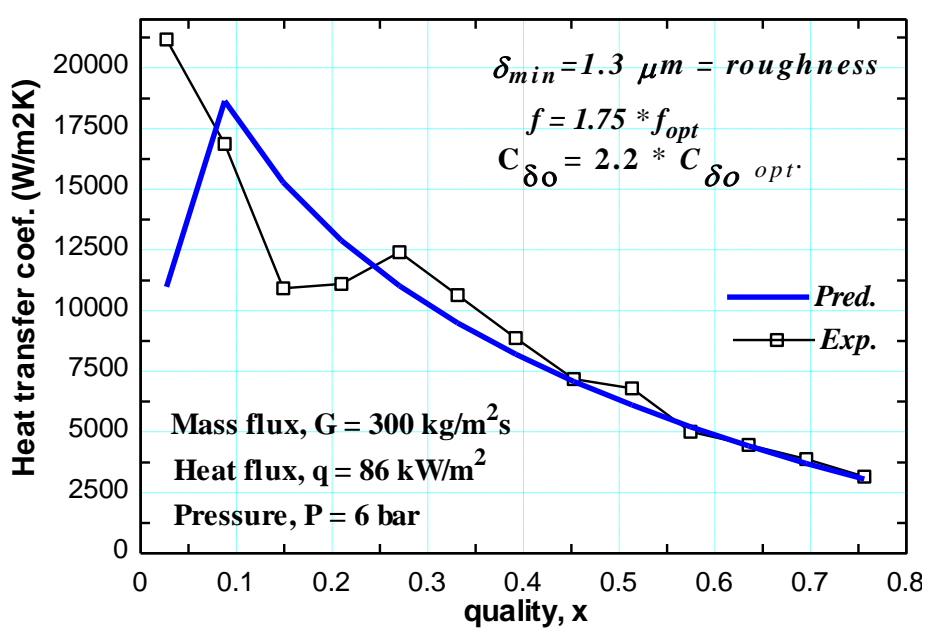

(d)

Figure 9: Sensitivity of the heat transfer coefficient to the three optimized parameters given by the model: a) frequency of bubble generation (b) Correction factor to the initial film thickness, (c) critical film thickness to dryout, (d) prediction of dryout when critical film thickness is same as roughness of the tube and the other two parameters are adjusted as shown.

\section{CONCLUSIONS}

A flow boiling experiment on $1.1 \mathrm{~mm}$ tube inside diameter using R134a was conducted and the results were compared with the state-of-the-art three-zone evaporation model.

The experimental results demonstrate that the heat transfer coefficient increases with heat flux and system pressure, but does not change with vapour quality when the quality is less than about $50 \%$. This is conventionally interpreted as evidence that nucleate boiling is the dominant heat transfer mechanism in this vapour quality range. For vapour quality values greater than $50 \%$ and at high heat flux, the heat transfer coefficient does not depend on heat flux and decreases with vapour quality. This could be caused by partial dryout.

A detailed analysis of the three-zone evaporation model of Thome et al. (2004) was presented in this paper based on current experiments. The model is based on convective heat transfer in the confined bubble regime, without any contribution from nucleate boiling. The model predicts fairly well experimental data that would be interpreted conventionally as nucleate boiling; especially the low pressure results. In its current form, the model over-predicts heat transfer in conditions in which partial dryout is thought to occur. The trend in the heat transfer coefficient with pressure changes is correctly predicted but the actual change is greater than that given by the model. Unlike the experimental results, the model shows a slight effect of mass flux on heat transfer coefficient. The model results are sensitive to the three parameters (bubble generation frequency, initial and end film thicknesses), which have to be optimised from experimental data. Some of the main important features of the model that may require modification include independent determination of the optimised parameters and an improvement of the partial dryout model.

\section{REFERENCES}

Bao, Z. Y., Fletcher, D. F. and Haynes, B. S., 2000, Flow boiling heat transfer of Freon R11 and HCFC123 in narrow passages, Int. Journal of Heat and Mass Transfer, Vol. 43, pp. 3347-3358.
Chen, L., Tian, Y.S. and Karayiannis, T.G., 2005, R134a Flow patterns in small-diameter tubes, J. Process Mechanical Engineering, Vol. 219, pp 167-181.

Chen, L., Tian, Y.S. and Karayiannis, T.G., 2006, The effect of tube diameter on vertical two-phase flow regimes in small tubes, Int. J. Heat and Mass Transfer, Vol. 49, pp. 4220-4230.

Churchill, S.W. and Usagi, R., 1972, A general expression for the correlation of rates of transfer and other phenomena, AIChE J. 18, pp. 1121-1128.

Cooper, M.G., (1984), Heat flow rate in saturated nucleate pool boiling--a wide-ranging examination using reduced properties, Advances in Heat Transfer, Vol. 16, Academic Press, Orlando, pp. 157-239.

Dupont, V., Thome, J. R., Jacobi, A.M., 2004, Heat transfer model for evaporation in microchannels., Part II: comparison with the database, Int. J. Heat and Mass Transfer, Vol. 47, pp. 3387-3401.

Huo, X., Tian, Y.S. and Karayiannis, T.G., 2007, R134a flow boiling heat transfer in small diameter tubes, In press, International Journal of Heat Exchangers.

Kenning, D.B.R. and Yan, Y., 2001, Saturated flow boiling of water in a narrow channel: experimental investigation of local phenomena, IChemE Trans. A, Chem. Eng. Res. and Design $79,425-426$.

Kew, P.A., Cornwell, K., 1996, On pressure fluctuations during boiling in narrow channels, $2^{\text {nd }}$ European Thermal-Science and $14^{\text {th }}$ UIT National Heat Transfer Conference, Rome2, 13231327.

Kew, P. and Cornwell, K., 1997, Correlations for the prediction of boiling heat transfer in small diameter channels, Applied Thermal Engineering Vol. 17, No. 8-10, pp. 705-715.

Lazarek, G. M. and Black, S. H., 1982, Evaporative heat transfer, pressure drop and critical heat flux in a small vertical 
tube with R-113, Int. J. Heat Mass Transfer, Vol. 25, No. 7, pp. 945-960.

Lin, S., Kew, P.A., and Cornwell, K., 2001, Two-phase heat transfer to a refrigerant in a $1 \mathrm{~mm}$ diameter tube, Int. J. Refrigeration, Vol. 24, pp 51-56.

Moriyama, K. and Inoue, A., 1996, Thickness of the liquid film formed by a growing bubble in a narrow gap between two horizontal plates, J. Heat Transfer, Vol. 118, pp 132-139.

Owhaib, W. and Palm, B., 2003, Flow boiling heat transfer in vertical circular microchannel tube, Eurotherm seminar no. 72, Valencia, Spain, 31 March-2 April.

Palm, B., 2003, Mini-and microchannel research in Sweden, Proceedings of $1^{\text {st }}$ ASME internaltional conference in microchannels and minichannels, Rochester, New York, pp 2531

Qu, W. and Mudawar, I., 2003, Flow boiling heat transfer in two-phase microchannel heat sinks-I. Experimental investigation and assessment of correlation methods, Int. J. heat and Mass Transfer, Vol. 46, pp. 2755-2771.

Shama, P. R., Lee, A., Harrison, T., Martin, E. and Krishina, N., 1996, Effect of pressure and heat flux on bubble departure diameters and bubble emission frequency, Grambling State University Technical report.

Shiferaw, D., Karayiannis, T.G. and Kenning, D. B. R., 2006, A comparison with the three-zone model for flow boiling heat transfer in small diameter tubes, $13^{\text {th }}$ International Heat Transfer Conference, Sydney, August 13-18, pp. BOI 16.

Thome, J. R., Dupont, V., Jacobi, A.M., 2004, Heat transfer model for evaporation in microchannels., Part I: presentation of the model, Int. J. Heat and Mass Transfer, Vol. 47, pp. $3375-$ 3385 .

Tran, T. N., Wambsganss M. W. and France D. M., 1996, Small circular- and rectangular-channel boiling with two refrigerants, Int. J. Multiphase Flow, Vol. 22, No. 3, pp. 485498.

Wambsganss, M. W., France, D. M., Jendraejczyk, J. A. and Tran, T. N., 1993, Boiling heat transfer in a horizontal smalldiameter tube, Journal of Heat Transfer, Vol. 115, pp. 963-972.

Wen, D.S., Kenning, D.B.R. and Yan, Y., 2002, Flow boiling of water in a narrow vertical channel at low mass flux: observations of local phenomena, Proc. $12^{\text {th }}$ International Heat Transfer Conference, Grenoble, vol. 3, pp. 773-778.

Yan, Y. Y. and Lin, T. F., 1998, Evaporation heat transfer and pressure drop of refrigerant R-134a in a small pipe, Int. J. Heat Mass Transfer, Vol. 41, pp. 4183-41.

Yan, Y. and Kenning, D.B.R., 1998, Pressure and temperature fluctuations during boiling in narrow channel, Eurotherm 62: Heat Transfer in Condensation and Evaporation, Grenoble, pp. 107-117.

Zhang, L., Goodson, K.E. and Kenny, T.W., 2004, Silicon microchannel heat sinks, theories and phenomena, chap. 5-7, Springer, Berlin.
Zhang, L., Wang, E.N., Goodson, K.E. and Kenny, T.W., 2005, Phase change phenomena in silicon microchannels, Int. J. Heat Mass Transfer, Vol. 48, pp. 1572-1582. 